\title{
Vertebral fracture: epidemiology, impact and use of DXA vertebral fracture assessment in fracture liaison services
}

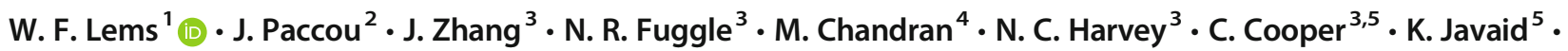 \\ S. Ferrari ${ }^{6} \cdot$ K. E. Akesson ${ }^{7} \cdot$ International Osteoporosis Foundation Fracture Working Group
}

Received: 21 October 2020 / Accepted: 16 December 2020 / Published online: 21 January 2021

(C) The Author(s) 2021

\begin{abstract}
Summary Vertebral fractures are independent risk factors for vertebral and nonvertebral fractures. Since vertebral fractures are often missed, the relatively new introduction of vertebral fracture assessment (VFA) for imaging of the lateral spine during DXAmeasurement of the spine and hips may contribute to detect vertebral fractures. We advocate performing a VFA in all patients with a recent fracture visiting a fracture liaison service (FLS). Fracture liaison services (FLS) are important service models for delivering secondary fracture prevention for older adults presenting with a fragility fracture. While commonly age, clinical risk factors (including fracture site and number of prior fracture) and BMD play a crucial role in determining fracture risk and indications for treatment with antiosteoporosis medications, prevalent vertebral fractures usually remain undetected. However, vertebral fractures are important independent risk factors for future vertebral and nonvertebral fractures. A development of the DXA technology, vertebral fracture assessment (VFA), allows for assessment of the lateral spine during the regular DXA bone mineral density measurement of the lumbar spine and hips. Recent approaches to the stratification of antiosteoporosis medication type according to baseline fracture risk, and differences by age in the indication for treatment by prior fracture mean that additional information from VFA may influence initiation and type of treatment. Furthermore, knowledge of baseline vertebral fractures allows reliable definition of incident vertebral fracture events during treatment, which may modify the approach to therapy. In this manuscript, we will discuss the epidemiology and clinical significance of vertebral fractures, the different methods of detecting vertebral fractures, and the rationale for, and implications of, use of VFA routinely in FLS.

Summary points

- Vertebral fracture assessment is a tool available on modern DXA instruments and has proven ability to detect vertebral fractures, the majority of which occur without a fall and without the signs and symptoms of an acute fracture.

- Most osteoporosis guidelines internationally suggest that treatment with antiosteoporosis medications should be considered for older individuals (e.g., 65 years + ) with a recent low trauma fracture without the need for DXA.

- Younger individuals postfracture may be risk-assessed on the basis of FRAX® probability including DXA and associated treatment thresholds.

- Future fracture risk is markedly influenced by both site, number, severity, and recency of prior fracture; awareness of baseline vertebral fractures facilitates definition of true incident vertebral fracture events occurring during antiosteoporosis treatment.

- Detection of previously clinically silent vertebral fractures, defining site of prior fracture, might alter treatment decisions in younger or older FLS patients, consistent with recent IOF-ESCEO guidance on baseline-risk-stratified therapy, and provides a reliable baseline from which to define new, potentially therapy-altering, vertebral fracture events.
\end{abstract}

W. F. Lems

wf.lems@amsterdamumc.nl

1 Amsterdam UMC, VU University Medical Center, Amsterdam, The Netherlands

2 Department of Rheumatology, Univ. Lille, CHU Lille, MABLab ULR 4490, 59000 Lille, France

3 MRC Lifecourse Epidemiology Unit, University of Southampton, Southampton, UK
4 Osteoporosis and Bone Metabolism Unit, Department of Endocrinology, Singapore General Hospital, Singapore, Singapore

5 Nuffield Department of Orthopaedics, Rheumatology and Orthopaedic Sciences, University of Oxford, Oxford, UK

6 Clinical Service and Research Laboratory of Bone Diseases, Hôpitaux Universitaires de Genève, Geneva, Switzerland

7 Department of Clinical Sciences and Department of Orthopaedics, Skane University Hospital, Lund University, Malmö, Sweden 
Keywords Vertebral fracture - Fracture liaison service (FLS) - Vertebral fracture assessment (VFA) - Osteoporosis . epidemiology $\cdot$ Bone mineral density (BMD)

\section{Introduction}

Osteoporosis is a chronic bone disease that is characterized by low bone mineral density (BMD), and deteriorated microarchitecture, leading to decreased bone quality and an increased susceptibility to fracture [1]. However, there are substantial diagnostic and treatment gaps in the field of osteoporosis globally, leading to a low percentage of the population worldwide who are at high risk of fracture being adequately assessed and treated for osteoporosis [2, 3]. Remarkably, the treatment gap appears to have widened in recent years (the so-called "crisis in osteoporosis") likely related to reimbursement, changes to healthcare policy and excessive concerns about very rare side-effects of antiosteoporosis medications, for example osteonecrosis of the jaw (ONJ) and atypical femur fractures (AFF) [4].

One of the most powerful approaches to fracture risk evaluation, and consequently to reduce the burden of fractures, is the fracture liaison service (FLS), in which (usually older) patients with a recent fragility fracture are screened for a high subsequent fracture risk by age, clinical risk factors and by BMD-measurement using DXA [5-8]. Such approaches are set out globally in the IOF Capture the Fracture ${ }^{\circledR}$ Programme [9]. However, using this strategy, prevalent vertebral fractures will not be detected. Importantly, developments in DXA instruments mean that it is now possible, using modern instruments, to detect prevalent vertebral fractures during the DXA assessment, with acquisition of a lateral view of the thoracic and lumbar spine, known as a vertebral fracture assessment (VFA), which is also called "Lateral Vertebral Assessment".

Recent guidance from IOF-ESCEO has demonstrated that antiosteoporosis therapy should optimally not just be a question of treatment or no treatment, but that the choice of a specific therapeutic intervention can be informed by the level of an agedependent baseline fracture probability [10]. Baseline risk, calculated using the FRAX® algorithm, with BMD if available, is substantially (2 to 5 times) higher, depending on site of fractures, number of prior fractures and their recency, as well as by other factors such as dose of corticosteroids [11]. In this context, for both older FLS patients whose general indication for therapy might be modified in terms of specific antiosteoporosis medication issued (e.g., anabolic for very high risk), and for younger FLS patients with treatment directly informed by FRAX probability with BMD, the detection of occult vertebral fractures by VFA might modify the final treatment decision. A further consideration is that a new vertebral fracture occurring on treatment is likely to be an indication for review of antiosteoporosis therapy [12]. Baseline VFA within the FLS care pathway provides knowledge of existing fractures and thus facilitates reliable definition of incident events. In this review article, we will explore the potential role of routine VFA in the FLS, in the context of the wider epidemiology of vertebral fractures, the performance characteristics of VFA for detection of vertebral fractures and, critically, emerging evidence for the clear importance of both site and recency of prior fracture for FRAX-based fracture risk assessment. We conclude with a suggested clinical approach to the use of VFA in FLS, which may improve risk stratification, and the basis for long-term care, in this vital secondary prevention setting.

\section{Epidemiology of vertebral fractures}

\section{Prevalence and incidence by age and sex}

The burden of vertebral fractures is immense with some prevalence estimates globally as high as $25-50 \%$ for individuals over the age of 50 years $[13,14]$ and with a prevalence, in some studies, higher than that of hip or wrist fracture (Fig. 1) [15]. However, the accurate description of the epidemiology of vertebral fractures is complicated by two main factors.

First, the fact that $65-75 \%$ are clinically "silent" [16] and only $30-40 \%$ of vertebral fractures come to medical attention [17]. Underrecognition and underdiagnosis occur, even by radiologists. Gehlbach et al. [18] showed in a population of 934 hospitalized postmenopausal women 60 years and over with chest radiographs that 132 vertebral fractures were diagnosed by two radiology experts, 65 fractures were described in the radiology report, and only 23 in the patient record, and in $25(18 \%)$ antiosteoporotic treatment was started [18]. Similarly, during a systematic review of lateral chest X-rays by an osteoporosis expert at the Geneva University hospital, the prevalence of vertebral fractures was $29 \%$, but only a third had been reported by radiologists [19].

Many VFs are discovered coincidentally on routine imaging. This is a particularly problematic situation when considering that (on plain radiography) the presence of vertebral fractures is often missed [20]. Second, various definitions of vertebral fractures exist, using clinical or morphometric parameters which significantly alter the population measures of disease [21]. The European Vertebral Osteoporosis Study (EVOS) (which included 15,000 individuals from 19 European countries) found an age-standardized population prevalence of $12.2 \%$ in women and $12.0 \%$ in men (aged 50-79 years) using the morphometric methods of McCloskey and Eastell to define vertebral deformity [21]. The Canadian Multicenter Osteoporosis Study (CaMos, a 


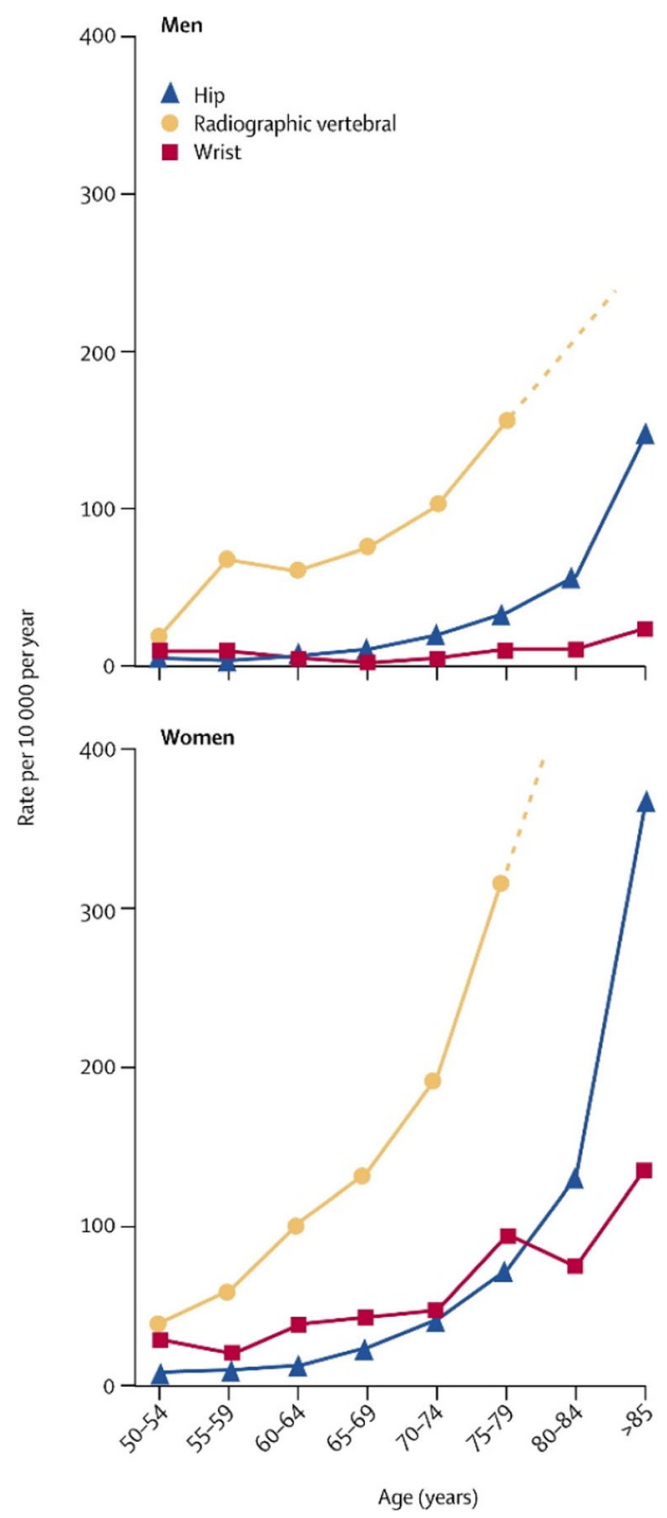

Fig. 1 The age distribution of hip, radiographic vertebral and hip fractures, reproduced with permission from Elsevier [15]

5-year follow-up of over 9000 participants) found a similar prevalence of vertebral fractures between the sexes with a male to female prevalence ratio of 1:1 [22]. In this study, the reference norms for vertebral shape was extracted from a subset of the population data, with any parameter greater than 3 standard deviations (SD) away from the mean indicating vertebral deformity within the whole data set. However, findings from the European Prospective Osteoporosis Study (EPOS, participants aged 75-79 years) suggested a higher incidence in men than women (29.3 vs 13.6 fractures per 100 person-years for men and women respectively) [23]. The definition of a vertebral fracture was a vertebra in which there was evidence of a $20 \%(+4$ $\mathrm{mm}$ ) or more reduction in anterior, middle, or posterior vertebral height between films. An additional requirement was that vertebra satisfy criteria for a prevalent deformity (using the
McCloskey-Kanis method) in the follow-up film. Finally, the Rotterdam Study found incidences of 1470 and 590 per 100,000 person years in women and men respectively using the McCloskey-Kanis method for vertebral fracture detection [24].

\section{Geographic variation}

Geographically, there is marked variation across the European continent with a 3 -fold difference in the prevalence of vertebral fracture in different countries, the highest being in Scandinavia (though this was partially explained by factors such as physical activity levels and measures of adiposity [21]). Geographical variation is observed across Latin America in the Latin American Vertebral Osteoporosis Study (LAVOS) which found an overall prevalence of $14.8 \%$ across the continent, but a significant difference between the highest country rate (in Mexico) and the lowest (in Puerto Rico) [25]. In Asian studies, there is generally greater variation in prevalence rates across the region, with a 1.42 difference between the highest prevalence rates in Vietnam and the lowest rates in China [26]. Across the globe, the highest age-standardized rates are seen in South Korea, USA, and Hong Kong, with the lowest rates in the UK [26].

\section{Vertebral fractures and mortality}

A vital element in the descriptive epidemiology of vertebral fractures is the associated increase in mortality which persists for more than a year postfracture $[27,28]$. In the UK, a study of a large, primary database observed a 12-month survival rate in women of $86.5 \%$ (vs $93.6 \%$ expected) and 5-year survival of $56.5 \%$ (vs $69.9 \%$ expected).

\section{Clinical significance of vertebral fractures}

\section{Vertebral fracture and risk of further fractures}

Previous studies have shown that prevalent vertebral fractures detected using spinal radiographs are predictive of future vertebral fractures and nonvertebral fractures [29,30]. Black et al. [29] reported in the Study of Osteoporotic Fractures, a prospective study of 9704 women aged 65 years or older that prevalent vertebral fractures were associated with a 5 -fold increased risk of sustaining a further vertebral fracture. Furthermore, the risks of hip and any nonvertebral fractures were increased with baseline prevalent fracture, with relative risks (RR) of 2.8 (95\% CI 2.3, 3.4) and 1.9 (95\% CI 1.7, 2.1), respectively. These associations remained significant after adjustment for age and calcaneal BMD [29]. Moreover, more severe or greater number of vertebral fractures were associated with higher fracture risk than milder or fewer vertebral 
fractures [29, 31, 32], independent of BMD [32]. In a large multinational study ( $n=2725$ postmenopausal women), the RR of new vertebral fracture increased with the number of baseline vertebral fractures [31]. Indeed, in subjects with a $\mathrm{VF}$ at baseline of the study, the risk of a new vertebral fracture within 1 year was 5 -fold that of women who did not have a baseline vertebral fracture $(\mathrm{RR}=5.1,95 \%$ CI 3.1-8.4). In the overall population, the incidence of a new vertebral fracture in the subsequent year after suffering an incident vertebral fracture was $19.2 \%$ (95\% CI 13.6-24.8\%) [31]. Thereby, the presence of a vertebral fracture greatly increases the risk of sustaining subsequent vertebral fractures, a phenomenon often referred to as "vertebral fracture cascade" $[31,33,34]$. In the retrospective case-series $(n=113,79.6 \%$ of women, median age 73) performed by Che et al. [34], vertebral fracture cascade was defined as an occurrence of at least three vertebral fractures within 1 year. Several authors found that those with at least one prevalent vertebral fracture on VFA had increased hazard ratios (HR) for incident clinical fractures [35-37]. Prince et al. [37] reported, in the setting of a randomized clinical trial "Calcium Intake Fracture Outcome Study (CAIFOS)", that those with one or more prevalent vertebral fractures on VFA had increased HR for incident clinical spine $(\mathrm{HR}=3.81 ; 95 \%$ CI 2.26-6.43, $p<0.05)$, hip (HR = 1.77; $95 \%$ CI 1.07-2.92, $p<0.05)$, and any fracture (HR $=1.54$; 95\% CI 1.09-2.16, $p<0.05$ ), independent of age and calcium/ placebo treatment [37].

\section{Vertebral fractures and quality of life}

Vertebral fractures have many potential consequences for the individual beyond economic cost; these risks include functional limitation, loss of independence, pain, impaired quality of life, higher inpatient healthcare utilization and diminished lifespan [38-43]. Health-related quality of life (HRQoL) has become an important tool used to assess the burden of disease imposed by chronic disease or disease events. Several studies have investigated the associations between HRQoL and back pain with prevalent vertebral fracture, detected by spine radiographs, but just a few have been population-based and have used VFA for diagnosing vertebral fracture [38-40, 44]. Among 1681 women and 1026 men aged $75-80$ years participating in a populationbased cross-sectional study (the Tromsø Study 20072008), VF was identified by VFA using DXA. Prevalent vertebral fracture was associated with back pain and reduced HRQoL in women, but not in men [44]. In a study of 751 women with and without vertebral fractures, diagnosed by spine radiographs, quality of life was assessed using the quality of life questionnaire of the International Osteoporosis Foundation (QUALEFFO-41), a measure containing questions in the domains of pain, physical function, social function, general health perception, and mental function. Women with vertebral fracture had significantly worse scores, which increased with number of vertebral fractures [45]. In a metaanalysis of 16 observational studies (including only one small study with men) including 3131 older osteoporotic patients with and without vertebral fractures the physical HRQoL was reported to be worse in people with vertebral fracture, even after accounting for age differences [46].

Studies investigating time since onset of vertebral fracture, and its effect on HRQoL, have shown that a residual effect lasts for up to 7 years postfracture [47, 48]. Furthermore, Johansson et al. [49] have shown, in a recent population-based cross-sectional study of 3028 Swedish women aged 78.8 years, that a (self-reported) clinical vertebral fracture was associated with lower physical HRQoL (12-Item Short-Form Health Survey (SF-12)). Moreover, the association remained for up to 18.9 years independently of covariates such as age, weight, height, smoking, prior stroke, mental HRQoL, grip strength, and lumbar spine BMD [49]. However, other studies have reported the contrary with improvement of the HRQoL within 2 to 4 years after onset of vertebral fracture $[50,51]$. The effect of recent VFs on HRQoL as measured by SF-12 in younger and older women has been investigated in a cohort of 86,128 postmenopausal women and the impact on physical HRQoL was similar between women $<65$ compared with those $\geq 65$ years of age [52]. There is some evidence that if more individuals affected by vertebral fractures were to be identified and were to receive treatment, the HRQoL would be improved [53]. Thus overall, it is apparent that vertebral fractures have a major impact on quality of life for many years after their occurrence.

\section{Methods for detection and interpretation of vertebral fractures}

\section{DXA VFA method}

Vertebral fracture assessment (VFA), using DXA, has been proposed as an alternative approach for the identification of vertebral fracture [54]. It consists of a lateral radiographic image of the thoracic and lumbar spine which can be easily and rapidly acquired via DXA scanning. The current conventional practice for initial vertebral fracture assessment is the use of the spinal radiographs [55] and images are taken from AP and lateral views of the thoracic and lumbar spine; more recent recommendations, for example the European Guidelines, accommodate the DXA-VFA approach [56]. Conventional spinal radiograph has remained the (gold) standard to which DXAVFA images are compared in studies establishing the validity and reproducibility of VFA [57-61]. There is good agreement between DXA-VFA and spinal radiographs ( $\mathrm{k}: 0.74-0.96$ ) for 
presence of vertebral fracture using the semiquantitative approach $[62,63]$. In comparison with conventional radiographs, DXA-VFA has several distinct advantages including lower cost, lower radiation exposure, less obliquity [54], and greater convenience for patients given it can be performed at the same time as BMD measurements. A typical patient may receive an effective dose of 0.7 millisievert (mSv) for a standard AP lumbar spine view radiograph [64] compared with $0.01 \mathrm{mSv}$ for a fan beam DXA [65], and $<0.001 \mathrm{mSv}$ for a pencil beam DXA [66]. VFA is a low dose technique with doses reported to be from 0.002 to about $0.05 \mathrm{mSv}$.

However, limitations of DXA-VFA include reduced image resolution with cortical edges and endplates, leading to fewer visualized vertebra, particularly affecting the thoracic spine between T4 and T6 [57, 60, 67], and reduced ability to detect "mild" fractures [58].

In a systematic review, the diagnostic accuracy of DXA-VFA was compared with that of spinal radiography for detection of VFs [68]. VFA was found to have a reasonable sensitivity and a much better specificity for VF detection on a per-vertebra level $(0.70-0.93$ and $0.95-$ 1.00 respectively), and the sensitivity and specificity on a per-patient basis were $0.65-1.00$ and $0.74-1.00$ respectively [68]. Moreover, DXA technology continues to evolve, from the 1 st generation machines using pencil beam to later models employing a wide or narrow fan beam, which has shortened the acquisition time and improved image quality [69]. Whilst there has been no direct comparison between the different models of DXA scanners with regards to VF detection, there have been numerous studies using different models of DXA scanners comparing with radiograph $[60,70,71]$. Diacinti and colleagues [70] used a later model of DXA scan, the Lunar iDXA, which yielded a much higher sensitivity and specificity per vertebra, $96.97 \%$ and $99.91 \%$ respectively, and equally high sensitivity and specificity on a per patient basis, $96.83 \%$ and $98.66 \%$ respectively. In fact, both the sensitivity and specificity increased further when focused on those $\geq 65$ years on a per-vertebra and per patient bases [70]. For Hologic DXA scanners, older models such as Delphi C/W yielded a low sensitivity (47\%) but a high specificity per vertebra (99\%) $[60,70]$. The use of Hologic Discovery, a later model, improved the sensitivity and specificity per vertebra to $83.6 \%$ and $99.1 \%$ respectively [71]. Computer-based deep learning methods have been developed for VFA, and a recent study including over 12,000 VFAs has reported an area under the receiver operating characteristic curve of 0.94 (95\% confidence interval $[\mathrm{CI}]: 0.93,0.95)$ for vertebral fracture detection [corresponding to a sensitivity of $87.4 \%$ (534 of 611) and specificity of $88.4 \%$ (2838 of 3211)] and performed comparably to the study radiologists (all who had more than 10 years of experience) [72].

\section{Other technologies for targeted and opportunistic identification of vertebral fractures: $\mathrm{CT}$, MRI, and SPECT}

\section{CT}

Whilst the focus of this review is on the use of DXA-VFA in FLS, it should be recognized that several other technologies might be usefully incorporated into a comprehensive strategy for vertebral fracture detection. One potential source of vertebral fracture case detection is computed tomography (CT). Scans of the thorax, pelvis, and abdomen often include spinal elements; however, vertebral fractures may be present but not identified or reported. Indeed, it has been estimated that only $13-16 \%$ of retrospectively confirmed vertebral fractures on CT scans are reported [73-75], likely due to the fact that they are incidental findings and not the primary purpose for the investigation. However, the prevalence and incidence of VFs can be high in studies for other diseases, as has been shown in a large survey of subjects with COPD [76]. Studies have shown a high correlation between trabecular vertebral attenuation values on $\mathrm{CT}$ images and DXA BMD values [77-80], however the high radiation dose (typical effective dose for an adult abdominal CT is 8 $\mathrm{mSv}$ ) [69] and higher cost mean that $\mathrm{CT}$ is best placed as an opportunistic secondary modality, rather than as a primary assessment tool. Recent advances in computer processing and computer vision have led to development of computer-based deep learning or active shape modelling to identify fractures. The accuracy afforded by such approaches is $89-97 \%$ [81-83].

\section{MRI}

Magnetic resonance imaging (MRI) permits acquisition of 3D images of the body, including characterization of vertebral fractures [84-86]. An advantage over CT is the lack of ionizing radiation and that information can be gained on recency of fracture, from the presence of edema; a major disadvantage is the much longer scan times, danger posed by ferromagnetic implants and frequently claustrophobiainducing gantry. With recent technological advances, newer sequences and higher field strength over the last decade, MRI now represents a further option to explore bone microarchitecture [87] and the role of bone marrow adiposity in osteoporosis using diffusion weighted imaging and MR spectroscopy [88]. The place of MRI in opportunistic identification of vertebral fractures is as yet not well defined, and more robust evidence from large, prospective, multicenter studies is needed to validate the results of small translational studies [54, 87]. 


\section{SPECT}

Single-photon emission computed tomography (SPECT) is a sensitive diagnostic tool that can aid the identification of bony abnormalities that may be difficult to adequately characterize through the use of other imaging modalities alone. An example is Bertolotti's Syndrome $[89,90]$. In recent years, the use of SPECT has been compared to MRI in terms of fracture detection and management $[91,92]$. In these small clinical studies, SPECT appears to be comparable to MRI in detecting fractures, particularly in the acute phase, and could be considered if MRI is contraindicated and plain radiography does not provide diagnostic certainty. Given the more specialist use of SPECT, it is unlikely to be usefully incorporated into an opportunistic pathway for detection of vertebral fractures.

\section{Classification of vertebral fracture: QM, SQ, Genant, and $A B Q$ methods}

The classification of vertebral fracture has evolved in the last six decades, with early works by Hurxthal [93] and Barnett and Nordin [94] using a morphometric basis, in which the focus is vertebral dimension. There have been attempts over the years to develop the morphological approach $[95,96]$, in which the focus is the changes observed at the vertebral endplate (including cortical changes). Pure morphometric measurement focuses on six points on the vertebral body: the anterior, middle, and posterior point of the upper and inferior endplates. The relative height reduction between the anterior or middle section of the upper and inferior endplates points compared to height of the posterior section or the height reduction of posterior section in comparison to the adjacent vertebra will give rise to the diagnosis of vertebral fracture. This allows the type of deformity to be described as wedge, compression, and biconcavity. There are numerous proposed quantitative morphometric (QM) methods to aid the classification of severity of the fracture [20,97, 98]. However, the most widely adopted approach is the semiquantitative (SQ) method proposed by Genant and colleagues in 1993 [99]. This approach requires a lateral image of either thoracic or lumbar spine then visually grade the height of the vertebra. The vertebra is graded as normal (grade 0 ), mildly deformed (grade 1: 20-25\% reduction in anterior, middle, or posterior height with 10-20\% reduction of vertebra area), moderately deformed (grade 2: 25-40\% reduction in anterior, middle, or posterior height with $20-40 \%$ reduction of vertebra area), and severely deformed (grade $3: \geq 40 \%$ reduction in anterior, middle, or posterior height with $\geq 40 \%$ reduction of vertebral area) [99]. The Genant SQ method includes visual assessment of height loss alongside with morphological change and assessment of the endplate, which incorporates a qualitative element. The algorithm-based qualitative (ABQ) method, proposed in 2004, was developed after observing new vertebral fractures always involved radiological changes at the vertebral endplate [95]. The ABQ method follows a series of steps which then results in three potential outcomes: (a) normal, (b) osteoporotic fracture, and (c) nonfracture deformity [95]. The ABQ approach fundamentally assumes all vertebral fractures will involve changes at the endplate therefore taking a morphologic approach but does not include changes in height [95].

\section{Limitations and thresholds in diagnosis of fracture}

Both the QM method and morphological approaches have constraints that reduce their usefulness in clinical setting. One major disadvantage of QM is its inability to distinguish nonfracture causes of vertebral deformities including Scheuermann's disease, Schmorl's nodes, development deformities, and Cupid's bow from fracture [54, 97]. This pitfall can be avoided by the use of an experienced clinician [97], however this may not be achievable in clinical practice at all times. Unfortunately, this weakness also affects the morphological approach [100], in which the ability to differentiate $\mathrm{x}$ ray beam rotation/artefact from endplate depression and cortical buckling is of paramount importance [54]. For vertebral deformity severity stratification, Genant SQ has the distinct advantage of overcoming the above constraint and allowing interpretation of follow-up radiographs as it has the capability to assess delta change in vertebral height [54]. The key to the ABQ method proposed by Jiang and colleagues [95] is that it has given structure to a qualitative method [100] which can be subjective. The structured qualitative approach will therefore improve the likelihood of reproducibility.

The prevalence of vertebral fracture will differ depending on the method used for classification. Recently, the Rotterdam Study found the prevalence of vertebral fracture was over three times higher using QM method compared to ABQ method [101]. The disparity was reduced in the CaMos study, using Genant SQ method in comparison to a modified ABQ (mABQ) approach, with Genant SQ method vertebral fracture prevalence just over twice as high as $\mathrm{MABQ}$ [102]. Here, the mABQ method incorporated the degree of vertebral height reduction as part of diagnostic criteria [102]. There is also variation in vertebral fracture site, Genant SQ/QM vertebral fractures were predominately located in mid-thoracic spine, whereas ABQ VFs were mostly in the thoracolumbar junction $[101,102]$. Overall, the agreement between morphometric and morphologic approaches for grade 2 or 3 vertebral fractures is high. Deng and colleagues [103] found participants with grades 2 and 3 Genant SQ VF and grades 2 and 3 endplate/ cortex fracture to have similar BMD, and both showed worsening BMD as the severity of fracture increased. In the same study, comparable prevalence of vertebral fractures was found using both methods for grades 2 and 3, however there was noticeable disparity at grade 1 between the two methods 
[103]. In The Rotterdam Study, the intermethod agreement between QM method and ABQ method would increase by 2 -fold when mild fractures were excluded [101]. Mild fractures were defined as deformities with height loss but intact endplates, using both methods.

\section{Significance of grade 1 fractures}

It remains uncertain whether mild vertebral fracture such as grade 1 Genant SQ VF should be included in fracture risk assessment. Recent data from Sweden showed grade 1 Genant SQ VFs was associated with increased risk of developing fracture and was independent of age, clinical factors, and femoral neck BMD in older women [104]. However, in the CaMos study, whilst prevalent grade 1 Genant SQ VF was associated with incident Genant SQ VF compared with those without prevalent Genant SQ VF, but grade 1 Genant SQ VF was not associated with incident nonvertebral MOF compared to those without prevalent Genant SQ VF [102]. In fact, prevalent grade $1 \mathrm{mABQ}$ VF had a higher association with incident Genant SQ VF than grade 1 Genant SQ VF [102]. On the surface, this suggests that endplate depression or cortical buckling may have a stronger association with future fracture risk than height loss. However, it has been observed that some Genant SQ VF do not have endplate or cortical involvement $[102,103]$. Deng and colleagues [103] found many grade 1 Genant SQ VF had no endplate/cortex involvement, and a number of grade 2 Genant SQ VF did not have endplate/ cortex involvement either. This opens the debate whether the categorical assumption that all vertebral fractures will have endplate involvement is true at all times. Further research into the pathogenesis of these vertebral changes and their specific associations is needed. Both the ISCD and the IOF recommend the use of Genant SQ method in vertebral fracture identification [54, 105]. The Vertebral Fracture Initiative from IOF recommend the use of the term "fracture" and avoid using apparent synonyms such as "collapse" for clarity [54], a concept supported by national guidelines [106]. It also clearly states the need for grading the severity of the fracture alongside the number of vertebral fractures [54]. Given the absence of straightforward data on the increased fracture risk after a prevalent grade 1 fracture and the uncertainty to detect grade 1 fractures, and the high propensity for agreement between grade 2 and grade 3 VFs using either morphometric or morphologic approach, in clinical practice it would be prudent to follow a threshold of grade 2 ( $\geq 25 \%$ ) (or $3 \geq 40 \%$ ), vertebral height loss as described by the Genant SQ method for identification of vertebral fracture, both in men and women. Nevertheless, when there is doubt about the presence or absence of a vertebral fracture, we suggest additional imaging techniques, which would most usually be a conventional radiograph.

\section{Current indications for vertebral fracture assessment by DXA}

The International Society for Clinical Densitometry (ISCD) has provided recommendations on defining and reporting fractures on VFA in its official position statements [105]. For the ISCD, the methodology used for vertebral fracture identification should be similar to standard radiological approaches and be provided in the report. Fracture diagnosis should be based on visual evaluation and include assessment of grade/severity and morphometry alone is not recommended because it is unreliable for diagnosis. Finally, for the ISCD, the Genant visual semiquantitative method is the current clinical technique of choice for diagnosing vertebral fracture with VFA, and the severity of deformity may be confirmed by morphometric measurement if desired [105]. Indications for following VFA with another imaging modality are also described, and it is important to recognize that VFA is designed to detect vertebral fractures and not other abnormalities. The IOF-ESCEO has recently provided European guidance for the diagnosis and management of osteoporosis in postmenopausal women including recommendations on VFA [56]. Lastly, the National Osteoporosis Foundation (NOF) released, in 2014, a clinician's guide to prevention and treatment of osteoporosis including indications for vertebral imaging [107]. The recommendations of all three are summarized in Table 1.

\section{Clinical approach to routine VFA in FLS secondary fracture prevention}

\section{Value of VFA in secondary prevention}

VFA is currently underused globally, possibly partly because its utility has been unclear to healthcare providers and payers. Indeed, the degree to which VFA is reimbursed varies markedly across global health care systems. However, in the nonFLS context, VFA has shown added value to clinical diagnosis of osteoporosis and its subsequent management [108-110]. Studies have shown that the addition of VFA altered the therapeutic management of $3-30.8 \%$ of cases [111-113]. Other studies have also demonstrated that prevalent vertebral fracture identified from VFA images predict subsequent fractures independent of BMD and other risk factors [36, 114]. The use of VFA enhances the assessment especially for those in the normal and osteopenic BMD range, where depending on the guideline followed, medication is unlikely to be initiated in the absence of demonstrable fracture history. Such considerations support the notion that VFA might be regarded as a routine part of DXA assessment regardless of the setting in primary or secondary prevention. 
Table 1 Indications for vertebral fracture assessment (VFA) by DXA to detect vertebral fracture

\begin{tabular}{|c|c|c|}
\hline $\begin{array}{l}\text { International Society for Clinical Densitometry } \\
\text { (ISCD) (ref 105) }\end{array}$ & $\begin{array}{l}\text { International Osteoporosis Foundation- The } \\
\text { European Society for Clinical and Economic } \\
\text { Aspects of Osteoporosis, Osteoarthritis and } \\
\text { Musculoskeletal Diseases (IOF-ESCEO) (ref 56) }\end{array}$ & $\begin{array}{l}\text { National Osteoporosis Foundation (NOF) } \\
\text { (ref 107) }\end{array}$ \\
\hline $\begin{array}{l}\text { Lateral Spine imaging with Standard Radiography } \\
\text { or Densitometric VFA is indicated when } \\
\text { T-score is }<-1.0 \text { and of one or more of the } \\
\text { following is present: } \\
\text { - Women age } \geq 70 \text { years or men } \geq \text { age } 80 \text { years } \\
\text { - Historical height loss }>4 \mathrm{~cm}(>1.5 \text { inches) } \\
\text { - Self-reported but undocumented prior vertebral } \\
\text { fracture } \\
\text { - Glucocorticoid therapy equivalent to } \geq 5 \mathrm{mg} \text { of } \\
\text { prednisone or equivalent per day for } \geq 3 \\
\text { months } \\
\text { Recommendations from the ISCD adult Official } \\
\text { Position Statement } 2019\end{array}$ & $\begin{array}{l}\text { VFA should therefore be } \\
\text { considered in high-risk individuals, using either } \\
\text { spine radiographs or lateral spine DXA imaging in } \\
\text { postmenopausal women: } \\
\text { - History of } \geq 4 \mathrm{~cm} \text { height loss } \\
\text { - Kyphosis } \\
\text { - Recent or current long-term oral glucocorticoid } \\
\text { therapy, } \\
\text { - BMD T-score } \leq-2.5 \text {. } \\
\text { - It should also be considered in individuals with a } \\
\text { history of non-vertebral fracture } \\
\text { Recommendations from the IOF-ESCEO: } \\
\text { European guidance for the diagnosis and } \\
\text { management of osteoporosis in postmenopausal } \\
\text { women }\end{array}$ & $\begin{array}{l}\text { Vertebral imaging should be performed: } \\
\text { In all women age } 70 \text { and older and all men age } \\
80 \text { and older if BMD T-score is } \leq-1.0 \text { at the } \\
\text { spine, total hip, or femoral neck. } \\
\text { In women age } 65 \text { to } 69 \text { and men age } 70 \text { to } 79 \text { if } \\
\text { BMD T-score is } \leq-1.5 \text { at the spine, total } \\
\text { hip, or femoral neck. } \\
\text { In postmenopausal women and men age } 50 \text { and } \\
\text { older with specific risk factors: } \\
\text { - Low-trauma fracture during adulthood (age } \\
50 \text { and older) } \\
\text { - Historical height loss (difference between the } \\
\text { current height and peak height at age } 20 \text { ) of } \\
1.5 \text { in. or more ( } 4 \text { cm) } \\
\text { - Prospective height loss (difference between } \\
\text { the current height and a previously } \\
\text { documented height measurement) of } 0.8 \text { in. } \\
\text { or more ( } 2 \text { cm) } \\
\text { - Recent or ongoing long-term glucocorticoid } \\
\text { treatment } \\
\text { If bone density testing is not available, vertebral } \\
\text { imaging may be considered based on age } \\
\text { alone. }\end{array}$ \\
\hline
\end{tabular}

\section{VFA in FLS: previous work}

Although worldwide many FLS exist, only a small number of studies have been performed on the additional value of VFA in patients with a fragility fracture and a DXA-measurement. However, it is important to note that, as will be described below, criteria for intervention may not uniformly depend upon the presence of a recent prior fracture, but may be further modified by the presence or absence of densitometrically confirmed osteoporosis. Within FLS there is clearly potential to further refine risk assessment using VFA: A UK FLS found a quarter of patients presenting with a nonhip nonvertebral fragility fracture have an undiagnosed vertebral fracture [109]. Furthermore, only $49.5 \%$ of those with undiagnosed vertebral fractures had BMD measurements diagnostic of osteoporosis [109]. Likewise Van der Velde and colleagues [110] found $20.9 \%$ participants with normal BMD had $\geq 1 \mathrm{VF}$, and $27.7 \%$ for those with osteopenia and the diagnosis for vertebral fractures from 2.3 to $26.2 \%$ ( $p<$ 0.001 ) and for grade 2 or more from 0.9 to $14.7 \%$ ( $p<$ $0.001)$. The first study on the use of VFA in the FLS is from Glasgow [115]: in a prospective study in 377 patients with a low trauma nonvertebral fracture, VFs were found in 83 patients $(25 \%)$; in 37 patients, 2 or more vertebral fractures were found. In osteoporotic patients, VFs were found in $42 \%$, and in $19.8 \%$ of osteopenic patients. Overall in the study, a change of management occurred in $8.9 \%$ of patients because of their underlying vertebral fracture. In a recent study from France, 141 patients 50 years or over with a recent fragility fracture were enrolled: $24(21 \%)$ of the patients had a one or more VF diagnosed using VFA [116]. The total number of VFs was 30: grade 1 in 20 patients, grade 2 in 7 patients (23\%), and grade 3 in 3 patients (10\%). In 18 out of the 24 patients with at least one $\mathrm{VF}$, osteoporosis medication was adapted (starting antiosteoporotic drugs in 16 patients, and intensification in 2 patients).

Thus, there are two FLS studies that showed that vertebral fractures can be detected in around $20 \%$ of patients, and in around $10 \%$ has consequences for treatment. Furthermore, in a Dutch study, it was shown that after the introduction of local guideline on the use of VFA in addition to DXA, the diagnosis of vertebral fractures increased from 2.2 to $26.2 \%$ for grade 1 , and from 0.9 to $14.7 \%$ to grade 2 . Including patients with osteopenia and a vertebral fracture increased the percentage of patients with an antiosteoporosis drugtreatment indication from 31.0 to $38.4 \%$ (a $25 \%$ increase): this again shows that with VFA more vertebral fractures were diagnosed, leading to the recognition of more highrisk patients and (thus) antiosteoporosis treatment indications. But also very importantly, the study showed that implementation was feasible: performing DXA increased from 4.6 to $97.1 \%$ [110]. 


\section{Clinical approach to VFA in FLS}

Whether DXA-VFA changes management decisions in FLS clearly depend upon local or national policy with regard to the criteria for treatment with antiosteoporosis medications. For example, in some guidelines, such as the Scottish SIGN, even after FRAX assessment or prior fracture, treatment is suggested when the BMD T-score is -2.5 or below. The limitations of this approach have been documented previously [117]. The recently published IOF-ESCEO European guidelines [56], consistent with the majority of guidelines internationally [118], suggest that in the context of a low trauma fracture, in older patients ( $>65$ years), antiosteoporosis treatment can usually be recommended without further assessment of BMD. Thus in this context, it might be considered that additional knowledge of prevalent vertebral fractures would be unlikely to change treatment decisions. Furthermore, in the calculation of fracture probability using FRAX, once prior fracture has been ticked, there is no means of incorporating further prior fractures as an input variable, which might otherwise be used to modify the approach in younger women, in whom commencement of treatment may be decided on FRAX probability [119]. However, it is apparent from previous and more recent work that both the number, timing, and site of prior fractures influence the risk of a future fracture [11, 120-122]. Thus a prior vertebral fracture conveys a greater risk of future vertebral or hip fracture than does a prior wrist fracture [122]; fracture risk increases markedly immediately after an index fracture and wanes over 2 years or so, to a more steady level which is still above that prior to the index fracture event [11]. The importance of these modifications has been recognized in the publication of adjustment factors for the FRAX algorithm [11], which allow the attending physician to account for recency and site of prior fracture in treatment decisions in the FLS. Furthermore, guidance recently published by IOF-ESCEO has set out new approaches to the stratification of treatment by baseline fracture risk [10]. Here, whilst the criteria for treatment are established on the basis of the current European guidelines, the decision as to which medication should be used is informed by an individual's fracture risk, derived using the FRAX calculator. For those at high-risk, antiresorptive therapy such as an oral or intravenous bisphosphonate may be recommended, but for those at very high risk (which might be reached through the detection of a vertebral fracture), an anabolic-first strategy may be employed. Consistent with the European guidelines, women 65 years or older with a recent low trauma fracture will usually warrant treatment regardless of their calculated FRAX probability, but modification of FRAX probability according to recency and site of fracture may push them into the very high-risk category, with anabolic therapy thus suggested. In younger patients, where the treatment decision is based on FRAX probability, this kind of modification (for example presentation with a wrist fracture but evidence of a vertebral fracture on DXA-VFA) might lead to movement between risk categories to either indicate treatment or type of treatment. Finally, an incident vertebral fracture on treatment may well be a strong indication that alternative treatment is required. Given that vertebral fractures are often silent, baseline detection of vertebral fractures using DXA-VFA in the FLS, provides vital information that allows the treating physician to classify any subsequent fractures reliably as incident rather than prior events [12]. Finally, the presence of vertebral fractures may influence treatment duration, with a higher risk of refracture following treatment cessation [123].

\section{Conclusion and future directions}

Despite evidence for the clinical effectiveness of secondary fracture prevention for vertebral fractures, translation of this knowledge into the real-world setting remains disappointing. The IOF Capture the Fracture Best Practice Framework, the leading global initiative aiming to break the fragility fracture cycle, defines essential and aspirational elements of service delivery for fracture care [5]. Other organizations such as the European League Against Rheumatism (EULAR) and the European Federation of National Associations of Orthopaedics and Traumatology (EFORT) have also recognized the importance of optimal acute care for the patients aged 50 years or over with a recent fragility fracture and the prevention of subsequent fractures in high-risk patients [7]. The centerpiece of the IOF Capture the Fracture campaign is the Best Practice Framework, which has 13 standards across five domains and these set an international benchmark for FLS. In a questionnaire-based study that aimed to capture the evidence for the actual implementation of each standard in populations and centers where a FLS had been set up [9], it was found that there were marked differences by domain with secondary fracture prevention best delivered for hip fractures and least for vertebral fractures. The findings show that secondary fracture prevention in the vertebral fracture group remains suboptimal, and that ongoing work is needed to close this care gap even within established services. Strategies to overcome this profound gap could include training for radiology trainees and specialists under vertebral fracture educational programs provided for by international organizations such as the ISCD and IOF. Furthermore, the importance of vertebral fractures is clearly recognized within the IOF/FFN/NOF patient level key performance indicators for FLS [124].

These studies illustrate that detecting prevalent vertebral fractures in patients with fragility fractures may help to close or at the very least narrow the care gap in fracture care [125, 126].

In conclusion, we propose that DXA-VFA be performed in all patients visiting a FLS: 
- To detect subclinical vertebral fractures, which may modify risk category and thus commencement or type and duration of therapy, depending on age and local criteria for intervention;

- To provide baseline assessment, based on which later incident vertebral fractures can be discriminated from prevalent fractures, critical to optimal treatment monitoring.

Acknowledgments This paper has been endorsed by the International Osteoporosis Foundation Committee of Scientific Advisors. The authors thank the members of the IOF Fracture Working Group for their helpful support and input, and Dr. Dominique Pierroz for editorial assistance.

\section{Compliance with ethical standards}

Conflict of interest WFL: received fees for lectures and advisory boards from Amgen, Eli Lilly, UCB, Pfizer, Galapagos and Curaphar; JZ: no conflict of interest; NRF: no conflict of interest; NCH: reports consultancy, lecture fees and honoraria from Alliance for Better Bone Health, AMGEN, MSD, Eli Lilly, Servier, Shire, UCB, Kyowa Kirin, Consilient Healthcare, Radius Health and Internis Pharma. CC: received lecture fees and honoraria from Amgen, Danone, Eli Lilly, GSK, Kyowa Kirin, Medtronic, Merck, Nestlé, Novartis, Pfizer, Roche, Servier, Shire, Takeda and UCB. MKJ: received fees for lectures and advisory boards from Amgen, UCB, KLA: Amgen, Astellas, Chugai, Renapharma, UCB.

Open Access This article is licensed under a Creative Commons Attribution-NonCommercial 4.0 International License, which permits any non-commercial use, sharing, adaptation, distribution and reproduction in any medium or format, as long as you give appropriate credit to the original author(s) and the source, provide a link to the Creative Commons licence, and indicate if changes were made. The images or other third party material in this article are included in the article's Creative Commons licence, unless indicated otherwise in a credit line to the material. If material is not included in the article's Creative Commons licence and your intended use is not permitted by statutory regulation or exceeds the permitted use, you will need to obtain permission directly from the copyright holder. To view a copy of this licence, visit http:// creativecommons.org/licenses/by-nc/4.0/.

\section{References}

1. Kanis JA (1994) Assessment of fracture risk and its application to screening for postmenopausal osteoporosis: synopsis of a WHO report. WHO Study Group. Osteoporos Int 4:368-381

2. Harvey NC, McCloskey EV, Mitchell PJ, Dawson-Hughes B, Pierroz DD, Reginster JY, Rizzoli R, Cooper C, Kanis JA (2017) Mind the (treatment) gap: a global perspective on current and future strategies for prevention of fragility fractures. Osteoporos Int 28:1507-1529

3. Kanis JA, Cooper C, Rizzoli R et al (2017) Identification and management of patients at increased risk of osteoporotic fracture: outcomes of an ESCEO expert consensus meeting. Osteoporos Int 28:2023-2034

4. Khosla S, Cauley JA, Compston J, Kiel DP, Rosen C, Saag KG, Shane E (2017) Addressing the crisis in the treatment of osteoporosis: a path forward. J Bone Miner Res 32:424-430

5. Akesson K, Marsh D, Mitchell PJ, McLellan AR, Stenmark J, Pierroz DD, Kyer C, Cooper C (2013) Capture the fracture: a best practice framework and global campaign to break the fragility fracture cycle. Osteoporos Int 24:2135-2152

6. Eisman JA, Bogoch ER, Dell R, Harrington JT, McKinney RE Jr, McLellan A, Mitchell PJ, Silverman S, Singleton R, Siris E (2012) Making the first fracture the last fracture: ASBMR task force report on secondary fracture prevention. J Bone Miner Res 27: 2039-2046

7. Lems WF, Dreinhöfer KE, Bischoff-Ferrari H et al (2017) EULAR/EFORT recommendations for management of patients older than 50 years with a fragility fracture and prevention of subsequent fractures. Ann Rheum Dis 76:802-810

8. Pflimlin A, Gournay A, Delabrière I, Chantelot C, Puisieux F, Cortet B, Paccou J (2019) Secondary prevention of osteoporotic fractures: evaluation of the Lille University Hospital's Fracture Liaison Service between January 2016 and January 2018. Osteoporos Int 30:1779-1788

9. Javaid MK, Kyer C, Mitchell PJ et al (2015) Effective secondary fracture prevention: implementation of a global benchmarking of clinical quality using the IOF Capture the Fracture(R) Best Practice Framework tool. Osteoporos Int 26:2573-2578

10. Kanis JA, Harvey NC, McCloskey E et al (2020) Algorithm for the management of patients at low, high and very high risk of osteoporotic fractures. Osteoporos Int 31:1-12

11. Kanis JA, Johansson H, Harvey NC, Gudnason V, Sigurdsson G, Siggeirsdottir K, Lorentzon M, Liu E, Vandenput L, McCloskey EV (2020) Adjusting conventional FRAX estimates of fracture probability according to the recency of sentinel fractures. Osteoporos Int 31:1817-1828

12. Diez-Perez A, Adachi JD, Agnusdei D et al (2012) Treatment failure in osteoporosis. Osteoporos Int 23:2769-2774

13. Genant H, Bouxsein ML, ICBIW G (2011) Vertebral fracture initiative. https://www.iofbonehealthorg/what-we-do/trainingand-education/educational-slide-kits/vertebral-fracture-teachingprogram

14. Melton LJ 3rd, Lane AW, Cooper C, Eastell R, O'Fallon WM, Riggs BL (1993) Prevalence and incidence of vertebral deformities. Osteoporos Int 3:113-119

15. Sambrook P, Cooper C (2006) Osteoporosis. Lancet 367:2010 2018

16. Fink HA, Milavetz DL, Palermo L, Nevitt MC, Cauley JA, Genant HK, Black DM, Ensrud KE (2005) What proportion of incident radiographic vertebral deformities is clinically diagnosed and vice versa? J Bone Miner Res 20:1216-1222

17. Cooper C, Atkinson EJ, O'Fallon WM, Melton LJ 3rd (1992) Incidence of clinically diagnosed vertebral fractures: a population-based study in Rochester, Minnesota, 1985-1989. J Bone Miner Res 7:221-227

18. Gehlbach SH, Bigelow C, Heimisdottir M, May S, Walker M, Kirkwood JR (2000) Recognition of vertebral fracture in a clinical setting. Osteoporos Int 11:577-582

19. Casez P, Uebelhart B, Gaspoz JM, Ferrari S, Louis-Simonet M, Rizzoli R (2006) Targeted education improves the very low recognition of vertebral fractures and osteoporosis management by general internists. Osteoporos Int 17:965-970

20. Eastell R, Cedel SL, Wahner HW, Riggs BL, Melton LJ 3rd (1991) Classification of vertebral fractures. J Bone Miner Res 6: 207-215

21. O'Neill TW, Felsenberg D, Varlow J, Cooper C, Kanis JA, Silman AJ (1996) The prevalence of vertebral deformity in european men and women: the European Vertebral Osteoporosis Study. J Bone Miner Res 11:1010-1018

22. Jackson SA, Tenenhouse A, Robertson L (2000) Vertebral fracture definition from population-based data: preliminary results from the Canadian Multicenter Osteoporosis Study (CaMos). Osteoporos Int 11:680-687 
23. Felsenberg D, Silman AJ, Lunt M et al (2002) Incidence of vertebral fracture in europe: results from the European Prospective Osteoporosis Study (EPOS). J Bone Miner Res 17:716-724

24. Van der Klift M, De Laet CE, McCloskey EV, Hofman A, Pols HA (2002) The incidence of vertebral fractures in men and women: the Rotterdam Study. J Bone Miner Res 17:1051-1056

25. Clark P, Cons-Molina F, Deleze M et al (2009) The prevalence of radiographic vertebral fractures in Latin American countries: the Latin American Vertebral Osteoporosis Study (LAVOS). Osteoporos Int 20:275-282

26. Ballane G, Cauley JA, Luckey MM, El-Hajj Fuleihan G (2017) Worldwide prevalence and incidence of osteoporotic vertebral fractures. Osteoporos Int 28:1531-1542

27. Bliuc D, Nguyen ND, Milch VE, Nguyen TV, Eisman JA, Center JR (2009) Mortality risk associated with low-trauma osteoporotic fracture and subsequent fracture in men and women. Jama 301: 513-521

28. Cooper C, Atkinson EJ, Jacobsen SJ, O'Fallon WM, Melton LJ 3rd (1993) Population-based study of survival after osteoporotic fractures. Am J Epidemiol 137:1001-1005

29. Black DM, Arden NK, Palermo L, Pearson J, Cummings SR (1999) Prevalent vertebral deformities predict hip fractures and new vertebral deformities but not wrist fractures. Study of Osteoporotic Fractures Research Group. J Bone Miner Res 14: 821-828

30. Ross PD, Genant HK, Davis JW, Miller PD, Wasnich RD (1993) Predicting vertebral fracture incidence from prevalent fractures and bone density among non-black, osteoporotic women. Osteoporos Int 3:120-126

31. Lindsay R, Silverman SL, Cooper C et al (2001) Risk of new vertebral fracture in the year following a fracture. Jama 285: 320-323

32. Siris ES, Genant HK, Laster AJ, Chen P, Misurski DA, Krege JH (2007) Enhanced prediction of fracture risk combining vertebral fracture status and BMD. Osteoporos Int 18:761-770

33. Briggs AM, Greig AM, Wark JD (2007) The vertebral fracture cascade in osteoporosis: a review of aetiopathogenesis. Osteoporos Int 18:575-584

34. Che H, Breuil V, Cortet B et al (2019) Vertebral fractures cascade: potential causes and risk factors. Osteoporos Int 30:555-563

35. Ferrar L, Roux C, Felsenberg D, Glüer CC, Eastell R (2012) Association between incident and baseline vertebral fractures in European women: vertebral fracture assessment in the Osteoporosis and Ultrasound Study (OPUS). Osteoporos Int 23: $59-65$

36. McCloskey EV, Vasireddy S, Threlkeld J, Eastaugh J, Parry A, Bonnet N, Beneton M, Kanis JA, Charlesworth D (2008) Vertebral fracture assessment (VFA) with a densitometer predicts future fractures in elderly women unselected for osteoporosis. J Bone Miner Res 23:1561-1568

37. Prince RL, Lewis JR, Lim WH, Wong G, Wilson KE, Khoo BC, Zhu K, Kiel DP, Schousboe JT (2019) Adding lateral spine imaging for vertebral fractures to densitometric screening: improving ascertainment of patients at high risk of incident osteoporotic fractures. J Bone Miner Res 34:282-289

38. Cauley JA, Lui LY, Paudel ML, Taylor BC, Cawthon PM, Hillier TA, Schousboe JT, McCulloch CE, Ensrud KE (2016) Impact of radiographic vertebral fractures on inpatient healthcare utilization in older women. Bone 88:165-169

39. Johansson L, Sundh D, Nilsson M, Mellström D, Lorentzon M (2018) Vertebral fractures and their association with health-related quality of life, back pain and physical function in older women. Osteoporos Int 29:89-99

40. Kendler DL, Bauer DC, Davison KS et al (2016) Vertebral Fractures: Clinical Importance and Management. Am J Med 129:221.e221-221.e210
41. Nevitt MC, Ettinger B, Black DM, Stone K, Jamal SA, Ensrud K, Segal M, Genant HK, Cummings SR (1998) The association of radiographically detected vertebral fractures with back pain and function: a prospective study. Ann Intern Med 128:793-800

42. Oleksik AM, Ewing S, Shen W, van Schoor NM, Lips P (2005) Impact of incident vertebral fractures on health related quality of life (HRQOL) in postmenopausal women with prevalent vertebral fractures. Osteoporos Int 16:861-870

43. Siggeirsdottir K, Aspelund T, Jonsson BY, Mogensen B, Launer LJ, Harris TB, Sigurdsson G, Gudnason V (2012) Effect of vertebral fractures on function, quality of life and hospitalisation the AGES-Reykjavik study. Age Ageing 41:351-357

44. Waterloo S, Søgaard AJ, Ahmed LA, Damsgård E, Morseth B, Emaus N (2013) Vertebral fractures and self-perceived health in elderly women and men in a population-based cross-sectional study: the Tromsø Study 2007-08. BMC Geriatr 13:102

45. Oleksik A, Lips P, Dawson A, Minshall ME, Shen W, Cooper C, Kanis J (2000) Health-related quality of life in postmenopausal women with low BMD with or without prevalent vertebral fractures. J Bone Miner Res 15:1384-1392

46. Al-Sari UA, Tobias J, Clark E (2016) Health-related quality of life in older people with osteoporotic vertebral fractures: a systematic review and meta-analysis. Osteoporos Int 27:2891-2900

47. Hallberg I, Bachrach-Lindström M, Hammerby S, Toss G, Ek AC (2009) Health-related quality of life after vertebral or hip fracture: a seven-year follow-up study. BMC Musculoskelet Disord 10:135

48. Hasserius R, Karlsson MK, Jonsson B, Redlund-Johnell I, Johnell O (2005) Long-term morbidity and mortality after a clinically diagnosed vertebral fracture in the elderly-a 12- and 22-year follow-up of 257 patients. Calcif Tissue Int 76:235-242

49. Johansson L, Svensson HK, Karlsson J, Olsson LE, Mellström D, Lorentzon M, Sundh D (2019) Decreased physical health-related quality of life-a persisting state for older women with clinical vertebral fracture. Osteoporos Int 30:1961-1971

50. Begerow B, Pfeifer M, Pospeschill M, Scholz M, Schlotthauer T, Lazarescu A, Pollaehne W, Minne HW (1999) Time since vertebral fracture: an important variable concerning quality of life in patients with postmenopausal osteoporosis. Osteoporos Int 10:2633

51. Kanis JA, Adachi JD, Cooper C et al (2013) Standardising the descriptive epidemiology of osteoporosis: recommendations from the Epidemiology and Quality of Life Working Group of IOF. Osteoporos Int 24:2763-2764

52. Brenneman SK, Barrett-Connor E, Sajjan S, Markson LE, Siris ES (2006) Impact of recent fracture on health-related quality of life in postmenopausal women. J Bone Miner Res 21:809-816

53. Langdahl BL, Ljunggren Ö, Benhamou CL et al (2016) Fracture rate, quality of life and back pain in patients with osteoporosis treated with teriparatide: 24-month results from the Extended Forsteo Observational Study (ExFOS). Calcif Tissue Int 99:259 271

54. Adams JE, Lenchik L, Roux C, Genant H (2010) Vertebral fracture initiative, Part II, radiological assessment of verttebral fracture. http://www.iofbonehealthorg/what-we-do/training-andeducation/educational-slide-kits/vertebral-fracture-teachingprogram. Accessed 8 Mar 2020

55. Ferrar L, Jiang G, Adams J, Eastell R (2005) Identification of vertebral fractures: an update. Osteoporos Int 16:717-728

56. Kanis JA, Cooper C, Rizzoli R, Reginster JY (2019) European guidance for the diagnosis and management of osteoporosis in postmenopausal women. Osteoporos Int 30:3-44

57. Bazzocchi A, Spinnato P, Fuzzi F, Diano D, Morselli-Labate AM, Sassi C, Salizzoni E, Battista G, Guglielmi G (2012) Vertebral fracture assessment by new dual-energy X-ray absorptiometry. Bone 50:836-841 
58. Fuerst T, Wu C, Genant HK et al (2009) Evaluation of vertebral fracture assessment by dual X-ray absorptiometry in a multicenter setting. Osteoporos Int 20:1199-1205

59. Rea JA, Li J, Blake GM, Steiger P, Genant HK, Fogelman I (2000) Visual assessment of vertebral deformity by X-ray absorptiometry: a highly predictive method to exclude vertebral deformity. Osteoporos Int 11:660-668

60. Schousboe JT, Debold CR (2006) Reliability and accuracy of vertebral fracture assessment with densitometry compared to radiography in clinical practice. Osteoporos Int 17:281-289

61. Vokes TJ, Dixon LB, Favus MJ (2003) Clinical utility of dualenergy vertebral assessment (DVA). Osteoporos Int 14:871-878

62. Diacinti D, Guglielmi G, Pisani D, Diacinti D, Argirò R, Serafini C, Romagnoli E, Minisola S, Catalano C, David V (2012) Vertebral morphometry by dual-energy X-ray absorptiometry (DXA) for osteoporotic vertebral fractures assessment (VFA). Radiol Med 117:1374-1385

63. Domiciano DS, Figueiredo CP, Lopes JB et al (2013) Vertebral fracture assessment by dual X-ray absorptiometry: a valid tool to detect vertebral fractures in community-dwelling older adults in a population-based survey. Arthritis Care Res 65:809-815

64. Wall BF, Hart D (1997) Revised radiation doses for typical X-ray examinations. Report on a recent review of doses to patients from medical X-ray examinations in the UK by NRPB. National Radiological Protection Board. Br J Radiol 70:437-439

65. Blake GM, Naeem M, Boutros M (2006) Comparison of effective dose to children and adults from dual X-ray absorptiometry examinations. Bone 38:935-942

66. Lewis MK, Blake GM, Fogelman I (1994) Patient dose in dual xray absorptiometry. Osteoporos Int 4:11-15

67. Damiano J, Kolta S, Porcher R, Tournoux C, Dougados M, Roux C (2006) Diagnosis of vertebral fractures by vertebral fracture assessment. J Clin Densitom 9:66-71

68. Lee JH, Lee YK, Oh SH et al (2016) A systematic review of diagnostic accuracy of vertebral fracture assessment (VFA) in postmenopausal women and elderly men. Osteoporos Int 27: 1691-1699

69. Damilakis J, Adams JE, Guglielmi G, Link TM (2010) Radiation exposure in X-ray-based imaging techniques used in osteoporosis. Eur Radiol 20:2707-2714

70. Diacinti D, Del Fiacco R, Pisani D et al (2012) Diagnostic performance of vertebral fracture assessment by the lunar iDXA scanner compared to conventional radiography. Calcif Tissue Int 91:335342

71. Hospers IC, van der Laan JG, Zeebregts CJ, Nieboer P, Wolffenbuttel BH, Dierckx RA, Kreeftenberg HG, Jager PL, Slart RH (2009) Vertebral fracture assessment in supine position: comparison by using conventional semiquantitative radiography and visual radiography. Radiology 251:822-828

72. Derkatch S, Kirby C, Kimelman D, Jozani MJ, Davidson JM, Leslie WD (2019) Identification of vertebral fractures by convolutional neural networks to predict nonvertebral and hip fractures: a registry-based cohort study of dual X-ray absorptiometry. Radiology 293:405-411

73. Bartalena T, Giannelli G, Rinaldi MF, Rimondi E, Rinaldi G, Sverzellati N, Gavelli G (2009) Prevalence of thoracolumbar vertebral fractures on multidetector CT: underreporting by radiologists. Eur J Radiol 69:555-559

74. Carberry GA, Pooler BD, Binkley N, Lauder TB, Bruce RJ, Pickhardt PJ (2013) Unreported vertebral body compression fractures at abdominal multidetector CT. Radiology 268:120-126

75. Williams AL, Al-Busaidi A, Sparrow PJ, Adams JE, Whitehouse RW (2009) Under-reporting of osteoporotic vertebral fractures on computed tomography. Eur J Radiol 69:179-183

76. van Dort MJ, Geusens P, Driessen JH, Romme EA, Smeenk FW, Wouters EF, van den Bergh JP (2018) High imminent vertebral fracture risk in subjects with COPD with a prevalent or incident vertebral fracture. J Bone Miner Res 33:1233-1241

77. Buckens CF, Dijkhuis G, de Keizer B, Verhaar HJ, de Jong PA (2015) Opportunistic screening for osteoporosis on routine computed tomography? An external validation study. Eur Radiol 25: 2074-2079

78. Löffler MT, Jacob A, Valentinitsch A, Rienmüller A, Zimmer C, Ryang YM, Baum T, Kirschke JS (2019) Improved prediction of incident vertebral fractures using opportunistic QCT compared to DXA. Eur Radiol 29:4980-4989

79. Pickhardt PJ, Pooler BD, Lauder T, del Rio AM, Bruce RJ, Binkley N (2013) Opportunistic screening for osteoporosis using abdominal computed tomography scans obtained for other indications. Ann Intern Med 158:588-595

80. Romme EA, Murchison JT, Phang KF, Jansen FH, Rutten EP, Wouters EF, Smeenk FW, Van Beek EJ, Macnee W (2012) Bone attenuation on routine chest $\mathrm{CT}$ correlates with bone mineral density on DXA in patients with COPD. J Bone Miner Res 27: 2338-2343

81. Al-Helo S, Alomari RS, Ghosh S, Chaudhary V, Dhillon G, AlZoubi MB, Hiary H, Hamtini TM (2013) Compression fracture diagnosis in lumbar: a clinical CAD system. Int J Comput Assist Radiol Surg 8:461-469

82. Lessmann N, van Ginneken B, de Jong PA, Išgum I (2019) Iterative fully convolutional neural networks for automatic vertebra segmentation and identification. Med Image Anal 53:142-155

83. Tomita N, Cheung YY, Hassanpour S (2018) Deep neural networks for automatic detection of osteoporotic vertebral fractures on CT scans. Comput Biol Med 98:8-15

84. Ahmadi SA, Takahashi S, Hoshino M et al (2019) Association between MRI findings and back pain after osteoporotic vertebral fractures: a multicenter prospective cohort study. Spine J 19: 1186-1193

85. Cortet B, Boutry N, Dubois P, Bourel P, Cotten A, Marchandise X (2000) In vivo comparison between computed tomography and magnetic resonance image analysis of the distal radius in the assessment of osteoporosis. J Clin Densitom 3:15-26

86. Link TM, Majumdar S, Augat P, Lin JC, Newitt D, Lu Y, Lane NE, Genant HK (1998) In vivo high resolution MRI of the calcaneus: differences in trabecular structure in osteoporosis patients. $\mathrm{J}$ Bone Miner Res 13:1175-1182

87. Chang G, Boone S, Martel D, Rajapakse CS, Hallyburton RS, Valko M, Honig S, Regatte RR (2017) MRI assessment of bone structure and microarchitecture. J Magn Reson Imaging 46:323337

88. Link TM (2012) Osteoporosis imaging: state of the art and advanced imaging. Radiology 263:3-17

89. Leone A, Cianfoni A, Cerase A, Magarelli N, Bonomo L (2011) Lumbar spondylolysis: a review. Skelet Radiol 40:683-700

90. Scharf S (2009) SPECT/CT imaging in general orthopedic practice. Semin Nucl Med 39:293-307

91. Li YB, Zheng X, Wang R, Wu H, Han S, Deng ZY, Sun D (2018) SPECT-CT versus MRI in localizing active lesions in patients with osteoporotic vertebral compression fractures. Nucl Med Commun 39:610-617

92. Querellou S, Arnaud L, Williams T et al (2014) Role of SPECT/ CT compared with MRI in the diagnosis and management of patients with wrist trauma occult fractures. Clin Nucl Med 39:813

93. Hurxthal LM (1968) Measurement of anterior vertebral compressions and biconcave vertebrae. Am J Roentgenol Radium Therapy, Nucl Med 103:635-644

94. Barnett E, Nordin BE (1960) The radiological diagnosis of osteoporosis: a new approach. Clin Radiol 11:166-174 
95. Jiang G, Eastell R, Barrington NA, Ferrar L (2004) Comparison of methods for the visual identification of prevalent vertebral fracture in osteoporosis. Osteoporos Int 15:887-896

96. Smith RW Jr, Eyler WR, Mellinger RC (1960) On the incidence of senile osteoporosis. Ann Intern Med 52:773-781

97. Chou SH, Vokes T (2016) Vertebral Morphometry. J Clin Densitom 19:48-53

98. Grados F, Marcelli C, Dargent-Molina P, Roux C, Vergnol JF, Meunier PJ, Fardellone P (2004) Prevalence of vertebral fractures in French women older than 75 years from the EPIDOS study. Bone 34:362-367

99. Genant HK, Wu CY, van Kuijk C, Nevitt MC (1993) Vertebral fracture assessment using a semiquantitative technique. J Bone Miner Res 8:1137-1148

100. Li S, Yao J (2014) Spinal imaging and image analysis. Springer International Publishing

101. Oei L, Koromani F, Breda SJ et al (2018) Osteoporotic vertebral fracture prevalence varies widely between qualitative and quantitative radiological assessment methods: the rotterdam study. J Bone Miner Res 33:560-568

102. Lentle BC, Berger C, Probyn L et al (2018) Comparative analysis of the radiology of osteoporotic vertebral fractures in women and men: cross-sectional and longitudinal observations from the Canadian multicentre osteoporosis study (CaMos). J Bone Miner Res 33:569-579

103. Deng M, Zeng XJ, He LC, Leung JCS, Kwok AWL, Griffith JF, Kwok T, Leung PC, Wáng YXJ (2019) Osteoporotic vertebral fracture prevalence in elderly Chinese men and women: a comparison of endplate/cortex fracture-based and morphometrical deformity-based methods. J Clin Densitom 22:409-419

104. Johansson L, Sundh D, Magnusson P, Rukmangatharajan K, Mellström D, Nilsson AG, Lorentzon M (2020) Grade 1 Vertebral Fractures Identified by Densitometric Lateral Spine Imaging Predict Incident Major Osteoporotic Fracture Independently of Clinical Risk Factors and Bone Mineral Density in Older Women. J Bone Miner Res

105. International Society for Clinical Densitometry (2019) ISCD Official Positions - Adult. https://wwwiscdorg/official-positions/ 2019-iscd-official-positions-adult/. Accessed Mar 82020

106. Adams J, Clark EM, Clunie G, et al (2017) Clinical guidance for the effective identification of vertebral fractures. https://theros.org. $\mathrm{uk} / \mathrm{media} / 3 \mathrm{daohfrq} / \mathrm{ros}$-vertebral-fracture-guidelines-november2017.pdf

107. Cosman F, de Beur SJ, LeBoff MS, Lewiecki EM, Tanner B, Randall S, Lindsay R (2014) Clinician's Guide to Prevention and Treatment of Osteoporosis. Osteoporos Int 25:2359-2381

108. Ginther JP, Ginther AW, Brodersen LD (2017) Adding VFA to DXA Identifies Fracture Risk in a Way Not Duplicated by Other Measures. Endocr Pract 23:1375-1378

109. Reniu AC, Ong T, Ajmal S, Sahota O (2017) Vertebral fracture assessment in patients presenting with a non-hip non-vertebral fragility fracture: experience of a UK Fracture Liaison Service. Arch Osteoporos 12:23

110. van der Velde RY, Bours SPG, Wyers CE, Lems WF, Geusens P, van den Bergh JPW (2017) Effect of implementation of guidelines on assessment and diagnosis of vertebral fractures in patients older than 50 years with a recent non-vertebral fracture. Osteoporos Int 28:3017-3022

111. Howat I, Carty D, Harrison J, Fraser M, McLellan AR (2007) Vertebral fracture assessment in patients presenting with incident nonvertebral fractures. Clin Endocrinol 67:923-930
112. Roux C, Baron G, Audran M, Breuil V, Chapurlat R, Cortet B, Fardellone P, Trémollières F, Ravaud P (2011) Influence of vertebral fracture assessment by dual-energy X-ray absorptiometry on decision-making in osteoporosis: a structured vignette survey. Rheumatology (Oxford, England) 50:2264-2269

113. Schousboe JT, Lix LM, Morin SN, Derkatch S, Bryanton M, Alhrbi M, Leslie WD (2019) Vertebral fracture assessment increases use of pharmacologic therapy for fracture prevention in clinical practice. J Bone Miner Res 34:2205-2212

114. Schousboe JT, Lix LM, Morin SN, Derkatch S, Bryanton M, Alhrbi M, Leslie WD (2019) Prevalent vertebral fracture on bone density lateral spine (VFA) images in routine clinical practice predict incident fractures. Bone 121:72-79

115. Gallacher SJ, Gallagher AP, McQuillian C, Mitchell PJ, Dixon T (2007) The prevalence of vertebral fracture amongst patients presenting with non-vertebral fractures. Osteoporos Int 18:185-192

116. Aboudiab M, Grados F, Batteux B, Henry-Desailly I, Fardellone P, Goëb V (2020) Vertebral fracture assessment (VFA) in patients over 50 years of age with a non-severe peripheral fracture. Osteoporos Int 31:1477-1486

117. Kanis JA, Compston J, Cooper C, Harvey NC, Johansson H, Odén A, McCloskey EV (2016) SIGN guidelines for Scotland: BMD versus FRAX versus QFracture. Calcif Tissue Int 98:417-425

118. Kanis JA, Harvey NC, Cooper C, Johansson H, Odén A, McCloskey EV (2016) A systematic review of intervention thresholds based on FRAX : a report prepared for the National Osteoporosis Guideline Group and the International Osteoporosis Foundation. Arch Osteoporos 11:25

119. Kanis JA, Harvey NC, Johansson H, Odén A, Leslie WD, McCloskey EV (2017) FRAX Update. J Clin Densitom 20:360 367

120. Kanis JA, Johansson H, Odén A et al (2018) Characteristics of recurrent fractures. Osteoporos Int 29:1747-1757

121. Kanis JA, Johnell O, De Laet C et al (2004) A meta-analysis of previous fracture and subsequent fracture risk. Bone 35:375-382

122. Klotzbuecher CM, Ross PD, Landsman PB, Abbott TA 3rd, Berger M (2000) Patients with prior fractures have an increased risk of future fractures: a summary of the literature and statistical synthesis. J Bone Miner Res 15:721-739

123. Black DM, Reid IR, Boonen S et al (2012) The effect of 3 versus 6 years of zoledronic acid treatment of osteoporosis: a randomized extension to the HORIZON-Pivotal Fracture Trial (PFT). J Bone Miner Res 27:243-254

124. Javaid MK, Sami A, Lems W et al (2020) A patient-level key performance indicator set to measure the effectiveness of fracture liaison services and guide quality improvement: a position paper of the IOF Capture the Fracture Working Group, National Osteoporosis Foundation and Fragility Fracture Network. Osteoporos Int

125. Wasfie T, Jackson A, Brock C, Galovska S, McCullough JR, Burgess JA (2019) Does a fracture liaison service program minimize recurrent fragility fractures in the elderly with osteoporotic vertebral compression fractures? Am J Surg 217:557-560

126. Mitchell P, Åkesson K, Chandran M, Cooper C, Ganda K, Schneider M (2016) Implementation of Models of Care for secondary osteoporotic fracture prevention and orthogeriatric Models of Care for osteoporotic hip fracture. Best Pract Res Clin Rheumatol 30:536-558

Publisher's note Springer Nature remains neutral with regard to jurisdictional claims in published maps and institutional affiliations. 